\title{
Status of the Jet High Frequency Pellet Injector
}

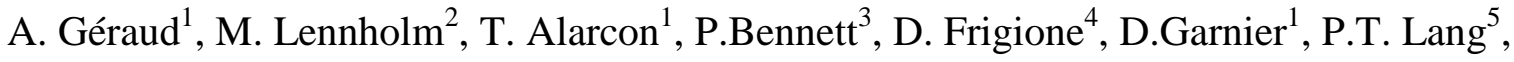 \\ A.Lukin ${ }^{6}$, R.Mooney $^{3}$, I.Vinyar $^{6}$ and JET-EFDA contributors* \\ JET-EFDA, Culham Science Centre, Abingdon, OX14 3DB, UK \\ ${ }^{1}$ CEA, IRFM, 13108, Saint Paul-Lez-Durance, France \\ ${ }^{2}$ JET-EFDA CSU, Culham Science Centre, Abingdon, Oxon OX143DB, UK \\ ${ }^{3}$ CCFE, Culham Science Centre, Abingdon, Oxon OX14 3DB, UK \\ ${ }^{4}$ ENEA, CP 65, Frascati, Rome, Italy \\ ${ }^{5}$ MPI für Plasmaphysik, 85748 Garching, Germany \\ ${ }^{6}$ PELIN LLC, 27 Gzhatskaya St., Saint-Petersburg, 195220, Russia \\ *See the Appendix of F. Romanelli et al., Proceedings of the $23^{\text {rd }}$ IAEA Fusion Energy Conference 2010, Daejon, Korea
}

\begin{abstract}
A new High Frequency Pellet Injector, part of the JET programme in support of ITER, has been installed on JET at the end of 2007. Its main objective is the mitigation of the Edge Localized Modes (ELMs), responsible for unacceptable thermal loads on the wall when their amplitude is too high. The injector was also required to have the capability to inject pellets for plasma fuelling. To reach this double goal, the injector has to be capable to produce and accelerate either small pellets to trigger ELMs (pace making), allowing to control their frequency and thus their amplitude, or large pellets to fuel the plasma. Operational since the beginning of the 2009 JET experimental campaign, the injector, based on the screw extruder technology, suffered from a general degradation of its performance linked to extrusion instability. After modifications of the nozzle assembly, recommissioning on plasma has been undertaken during the first half of 2012 and successful pellet ELM pacing was achieved, rising the intrinsic ELM frequency up to 4.5 times.
\end{abstract}

Keywords: deuterium pellet injector, ELM mitigation, JET-EP2, pellet fuelling

\section{Introduction}

A High Frequency Deuterium Pellet Injector, part of the JET programme in support of ITER (JET EP2), has been installed on JET at the end of 2007. Its main objective is the mitigation of the Edge Localised Modes, responsible for unacceptable thermal loads on plasmafacing components, and especially the new Beryllium wall, when their amplitude is too high (energy loss for each ELM up to $10 \%$ of the plasma energy content). Indeed it was demonstrated on the ASDEX UPGRADE Tokamak that the ELM frequency can be imposed by the pellet injection frequency [1]. The energy ejected during each ELM being inversely proportional to their frequency, the capacity of injecting small pellets at typically three times (up to $50 \mathrm{~Hz}$ ) the intrinsic ELM frequency was the main performance required for the injector. Moreover this injector was also required to have the capability to inject large pellets for plasma fuelling. It was designed and built by PELIN LLC (St Petersburg, Russia) on the basis of the screw extruder technology developed by this company and previously used on the pellet injectors installed on LHD [2] in Japan and on Tore Supra [3] in France. Nevertheless producing an injector able to reliably produce either small or large pellets (with a factor of typically 25 between the two volume ranges) and a maximum extruded ice flow close to the ITER pellet injector requirement, was really a technical challenge. The injector was installed as scheduled in the JET torus hall and successfully locally tested, firing pellets using the target position of the selector (see section 3) in asynchronous mode. Nevertheless an instability in the extrusion process was found for small pellets [4]. During the following commissioning on plasma, triggers coming from the JET control system at random times with respect to the extrusion start order, it became obvious that this extrusion instability, was a serious limitation to get a good reliability for small pellets. PELIN had to modify the bottom part of the screw extruder, which was done during the 2010-11 JET shut down. Commissioning on plasma restarted with the 2012 JET campaign.

The paper describes the present design of the whole injection system together with recent results of fuelling and ELM pacing experiments

\section{The Pellet Injector}

The modified injector now in operation remains very close to the prototype designed at the beginning of the project [5]. A schematic drawing is shown on Fig.1. A single screw extruder produces either one continuous large ribbon of ice or two simultaneous continuous narrow ribbons. In the new design, the problem of extrusion instability mentioned above has been solved by replacing the two small holes in the movable plate used to select the range and size of the pellets, by a plate equipped with only one small hole coupled to a blade to split the ribbon in two (fig. 2) [4]. A set of electromagnetic cutters and fast valves controlling short pulses of propellant gas (helium up to 20 bar) is used to respectively cut and accelerate the pellets. 


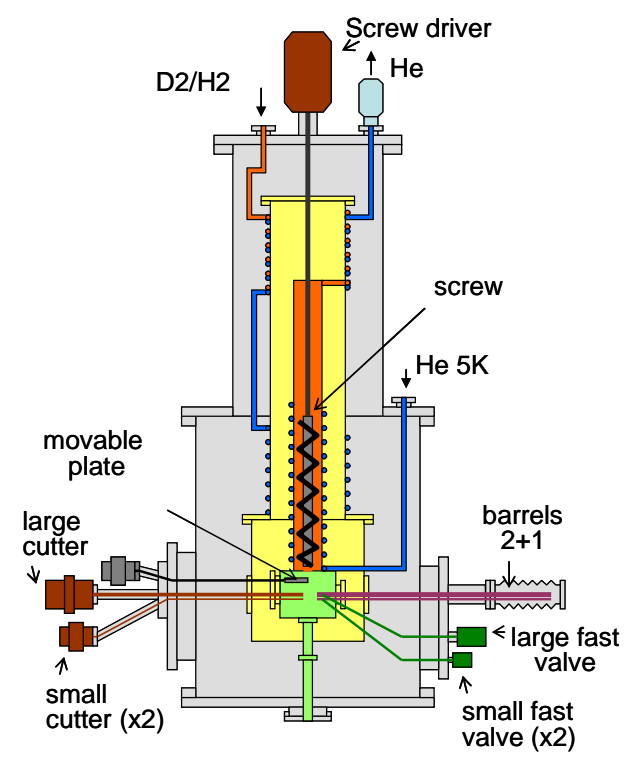

Fig.1: Schematic drawing of the PELIN pellet injector

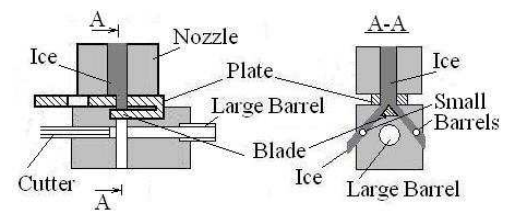

Fig.2: Schematic drawing of the modified extruder nozzle section

The high injection frequency for the small pellets is obtained by cutting alternatively pellets in the two small ribbons of ice. The diameter of the small pellets has also been increased from $1.2 \mathrm{~mm}$ to $1.5 \mathrm{~mm}$ in order to compensate the strong erosion occurring in the injection line and flight tubes, observed during the 2009-2010 experiments. The maximum deuterium /hydrogen ice production rate of the installed system is $1400 \mathrm{~mm}^{3} / \mathrm{s}$, consistent with the delivery of large pellets at $15 \mathrm{~Hz}$, the most demanding mode in term of ice flow. The extrusion velocity through both small and large channels is estimated to $60-80 \mathrm{~mm} / \mathrm{s}$. The extruder is cooled down by cold helium gas at a temperature of about $5 \mathrm{~K}$ provided by a 1000 litres Dewar pressurized by a $40 \mathrm{~W}$ heater able to evaporate up to $50 \mathrm{l} / \mathrm{h}$ [4]. The measured maximum liquid helium consumption is 20 $1 / \mathrm{h}$. The injector system is controlled by a Schneider
Modicon Premium Programmable Logic Controller connected by http links to the JET control system (Codas) acting as a user interface.

\section{Injection line and pumping system}

The pellet injector is connected to the JET torus through an injection line and flight tubes. The injection line allows i) pumping the propellant gas in its first stage, ii) selection of the flight tube to be used, iii) measurement in-flight of the pellet mass and iv) pumping of a part of the gas produced by the pellet erosion inside the flight tubes. The design details are given in [4]. The injection line includes a fast 4-way selector able to change the flight tube to be used from any of the initial position (target or previously selected flight tube) in less than $50 \mathrm{~ms}$. Three flight tubes are available to inject pellets either from the Low Field Side (LFS), or from the High Field Side (HFS), never tested so far, or from a Vertical High Field Side (VHFS) injection point. The flight tubes are composed of stainless steel tubes sections (ID $10 \mathrm{~mm}$, inner finish of $0.8 \mu \mathrm{m}$ ) with tapered entrance $\left(\right.$ angle $<1^{\circ}$ ) downstream to gaps necessary for tubes unions, valves or microwave cavities, taking into account a pellet trajectory spread of $1^{\circ}$ at the exit of the upstream section. All radii of curvature are at least $0.5 \mathrm{~m}$ and the total conveyance distances are respectively about $9 \mathrm{~m}$ and $18 \mathrm{~m}$ for the LFS and VHFS from the injector exit. The last section of the LFS flight tube installed inside an ICRH antenna is a little bit tortuous due to the geometry of the antenna. Fig. 3 shows the pumping system associated with the injector, the injection line and the 2 used flight tubes. Thanks to the differential pumping system and its large pumping capacity, no trace of helium propellant gas is found in the plasma. The VHFS flight tube is permanently pumped by a turbomolecular pump (TMP) except when used to inject pellets. In that case, the roots group takes over, the pressure in the line being liable to reach 1 mbar due to the pellet erosion. Interlocks based on the pressure measured in the volume pumped by the two large TMPs or in the VHFS flight tube enable the opening of the torus valves. For safety reasons (0.5 1 of solid or liquid hydrogen being stored in the extruder) buffer chambers $(2 \times 1001)$ are connected to the extruder inlet and outlet.

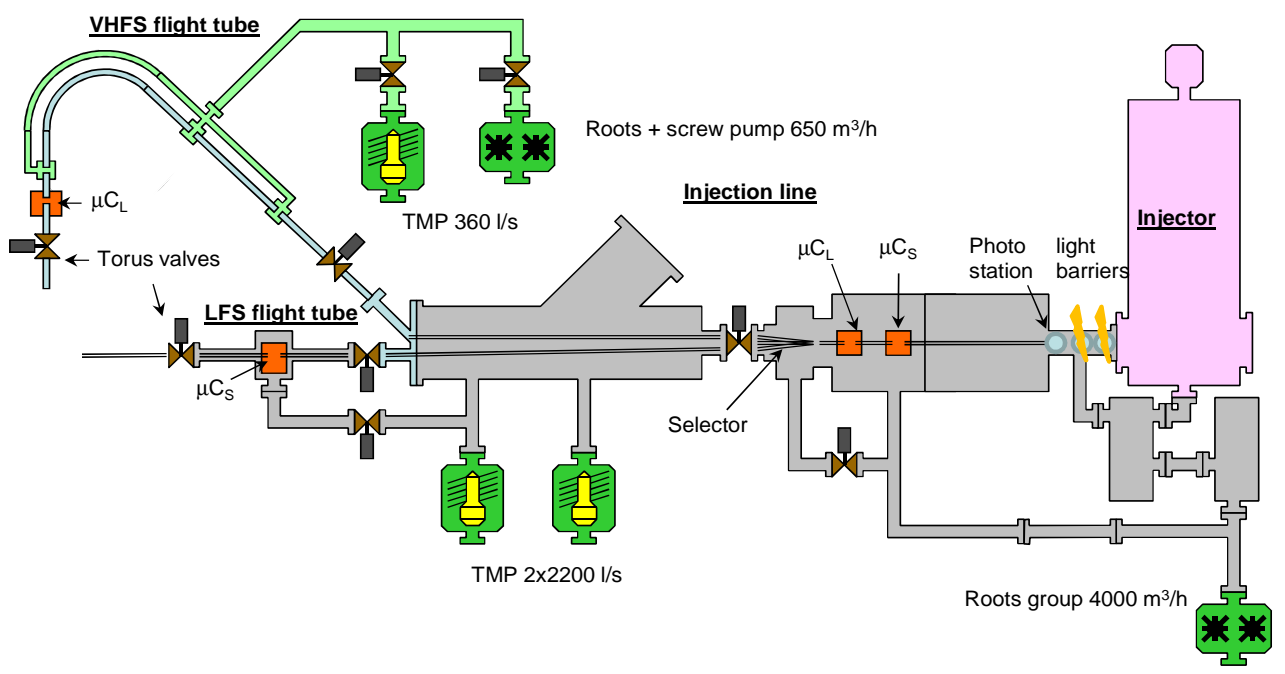

Fig.3: Simplified pumping diagram of the whole system 


\section{Pellet diagnostics and system performance}

The pellet injection system is equipped with a set of diagnostics aiming to help in the injector operation and to measure the injection parameters. From the injector to the torus end of the flight tubes we find : 1) a CCD camera to monitor the quality and the dimensions of the extruded ice as well as the extrusion speed (viewing part of the inner rectangle on Fig.1). Fig 4 shows a picture of the two small ribbons and a picture of the large ribbon; 2) another CCD camera, coupled to a set of light barriers for pellet velocity measurement, installed at the injector exit. Specific software has been developed by PELIN to re-construct the pellet volume from a CCD picture, recording a combination of two mutually perpendicular views of the pellets (Fig.5); 3) microwave cavities for pellet size measurement, produced by ORNL [6] to complement the optical system $\left(\mu \mathrm{C}_{\mathrm{S}}\right.$ and $\mu \mathrm{C}_{\mathrm{L}}$ on Fig.3). Two cavities are installed downstream from the PELIN diagnostic chamber, respectively tuned for small $\left(\mu \mathrm{C}_{\mathrm{S}}\right)$ and large $\left(\mu C_{L}\right)$ pellets. Two other cavities are installed at the end of the LFS (tuned for small pellets) and VHFS flight tubes (tuned for large pellets). After calibration, the height of the gaussian shape signal gives the volume of each pellet. This set of diagnostics allows locating higher breaking risk zones and estimating the erosion/slowing down rates during the pellet transportation from the injector to the plasma. In this way the average pellet velocity in the last section of the LFS flight tube (between the cavity and the plasma) has been calculated to be half (54\% for large pellets and $46 \%$ for small ones) the launch velocity.

The capability of the system is summarized in table 1. It shows the performance of the injector measured during the acceptance test performed after the nozzle modification and the performance of the whole system measured so far on plasma in JET pulse synchronized mode. Fig.6 shows typical velocity and size distributions measured during local commissioning tests, as determined by the light barriers and the picturebased volume re-construction.

A statistical analysis has been carried out for a series of 15 discharges (total of 855 pellets requested) in which pacing pellets were injected at $30-50 \mathrm{~Hz}$ through the LFS line for ELM pacing experiments. Individual pellets were traced through the flight as they were observed in the light barriers, in 2 microwave cavities and finally as they arrived in the plasma, observed by a high speed visible camera. Based on the observation of the various locations it was concluded that for the requested pellet size, frequency and velocity: 1) $\sim 85 \%$ of the requested pellets are seen by the microwave

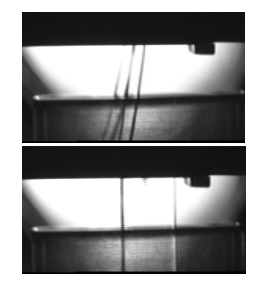

Fig.4: Extruded ice (top 2 small ribbons, bottom large ribbon)

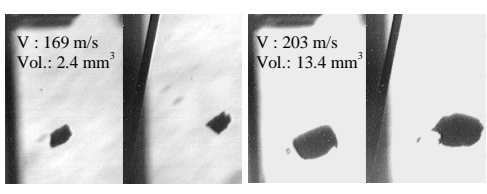

Fig.5: Double picture of a small (\#83233-114) and of a "mini" large pellet (\#83226-39) in flight

\begin{tabular}{|l|l|l|}
\hline \multicolumn{1}{|c|}{ Parameter } & $\begin{array}{l}\text { Injector performance in } \\
\text { local mode (acceptance } \\
\text { test) }\end{array}$ & $\begin{array}{l}\text { Overall system } \\
\text { performance reached } \\
\text { on plasma so far }\end{array}$ \\
\hline Nb pellet/pulse & unlimited & unlimited \\
\hline Pellet material & Hydrogen, deuterium & Hydrogen, deuterium \\
\hline $\begin{array}{l}\text { Pellet Volume } \\
\text { pacing (1) } \\
\text { fuelling(2) }\end{array}$ & $\begin{array}{l}2.2 \text { to } 3.2 \mathrm{~mm}^{3}(\mathrm{~d}=1.5, \mathrm{~L}=1.4 \text { to2) } \\
40 \text { to } 65 \mathrm{~mm}^{3}(\mathrm{~d}=4, \mathrm{~L}=3.2 \text { to } 5)\end{array}$ & $\begin{array}{l}2.4 \text { to } 3.2 \mathrm{~mm}^{3} \\
35 \text { to } 60 \mathrm{~mm}^{3}\end{array}$ \\
\hline Injection frequency & $\begin{array}{l}\text { up to } 50 \mathrm{~Hz} \text { for (1) } \\
\text { up to } 15 \mathrm{~Hz} \text { for (2) }\end{array}$ & $\begin{array}{l}\text { up to } 50 \mathrm{~Hz} \text { for (1) } \\
\text { up to } 15 \mathrm{~Hz} \text { for (2) }\end{array}$ \\
\hline Pellet velocity & $\begin{array}{l}80 \text { to } 200 \mathrm{~m} / \mathrm{s}(1) \\
100 \text { to } 300 \mathrm{~m} / \mathrm{s}(2)\end{array}$ & $\begin{array}{l}75 \text { to } 270 \mathrm{~m} / \mathrm{s}(1) \\
70 \text { to } 190 \mathrm{~m} / \mathrm{s}(2)\end{array}$ \\
\hline $\begin{array}{l}\text { Reliability at } \\
\text { injector exit } \\
\text { for medium size and } \\
\text { peed) }\end{array}$ & $>90 \%(1)$ & $\begin{array}{l}90-100 \%(1) \\
80 \%(2)\end{array}$ \\
\hline $\begin{array}{l}\text { Reliability on } \\
\text { plasma }\end{array}$ & $>95 \%(2)$ & $\begin{array}{l}\text { Aver.30\%, up to } 60 \% \text { (1) } \\
\text { Average } 80-90 \%(2)\end{array}$ \\
\hline
\end{tabular}

Table 1: Performance of the operated system in 2012
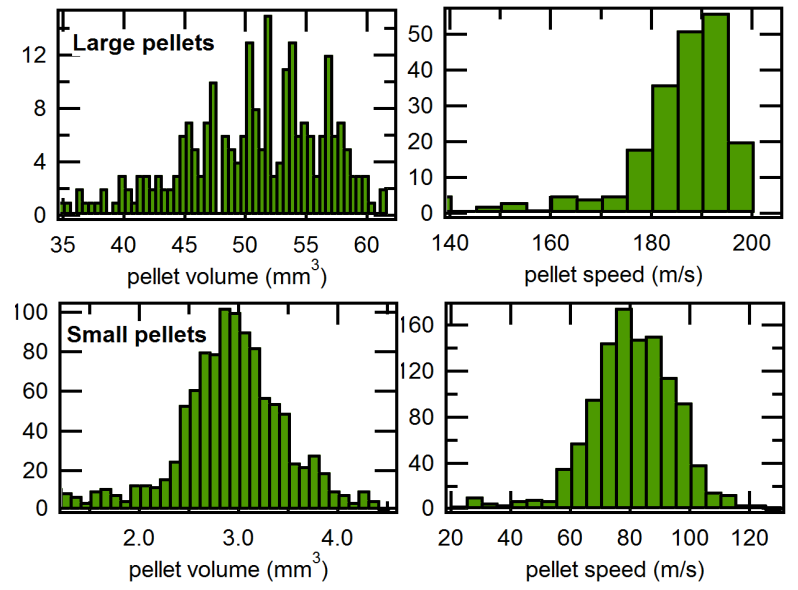

Fig.6: pellet velocity and volume distributions for two typical injection sequences at $10 \mathrm{~Hz}$ (large pellets - top) and $50 \mathrm{~Hz}$ (small pellets - bottom)

cavity near the PELIN device, 2 ) only $\sim 30 \%$ of the pellets arrive in the plasma in a 'healthy' state, 3) the majority of the 'lost pellets' were lost between the second microwave cavity (located where the flight line enters the JET vacuum vessel) and the plasma itself. From these observations it is clear that an improvement to the flight line geometry is required. The largest gain is likely to be made by improving the part of the flight line situated in the vacuum vessel, though improving the ex-vessel part of the flight line could also improve the pellet delivery. Studies are being undertaken to improve the ex-vessel flight line over the coming months. A more substantial improvement, concentrating on the invessel flight path is under consideration for 2013.

\section{Recent results of experiments on plasma}

5.1 Fuelling experiments : after a short commissioning phase on plasma, most of the injection experiments carried out during the 2012 C29-30 campaigns were devoted to ELM pacing. Nevertheless a few L-mode pulses have been fuelled with large pellets at $10-15 \mathrm{~Hz}$. Fig.7 shows time traces of pellet parameters and plasma density for a typical pulse fuelled by "mini" large pellets fired at $10 \mathrm{~Hz}$, without feedback control of the plasma density, not yet implemented. $97 \%$ of the 90 requested pellets are 


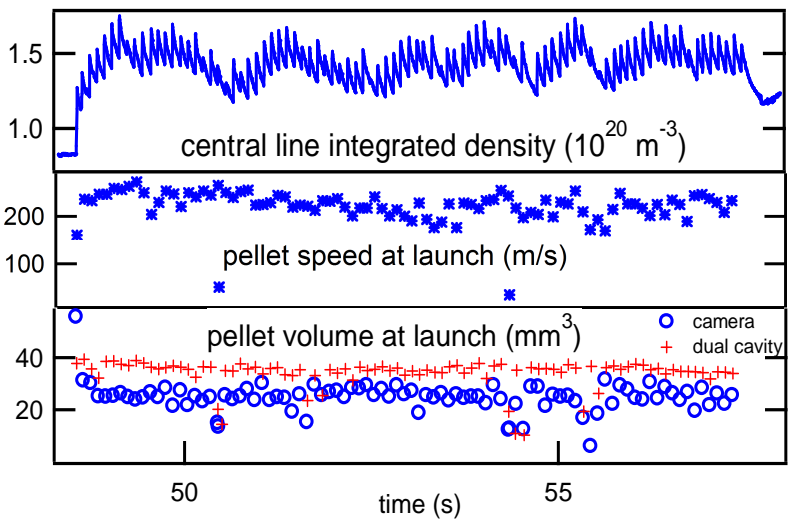

Fig.7: Typical plasma density (JPN 82377) resulting of injection of "mini" large pellets at $10 \mathrm{~Hz}$

visible on the plasma density, $88 \%$ having a volume $>50 \%$ averaged volume.

5.2 Pacing experiments: Fig. 8 illustrates the pacing effect obtained by injection of small pellets in a H-mode discharge. As expected no fuelling and no confinement degradation are observed and a short sequence exhibiting consecutive ELM synchronized with pellets can be seen. In the series of ELM pacing discharges, described above only about half of the pellets which arrived in the plasma triggered ELMs. A statistical analysis was undertaken to assess the influence on the ability of pellets to trigger ELMs of the following parameters: 1) the time elapsed between the previous ELM and the arrival of the pellet, 2) The pellet size, as indicated by the camera signal amplitude and 3) the pellet velocity - determined from the flight time between the second Microwave Cavity and the plasma. It should be mentioned that there is a fairly significant velocity scatter, which lead to pellets arriving at the plasma at fairly random intervals, making a statistical approach appropriate. Figure 9 shows the result of this analysis. Figure $9 a$, shows the probability of a pellet triggering an ELM as a function of the time elapsed since the previous ELM. Pellets arriving less than 10$20 \mathrm{~ms}$ after the previous ELM are seen to be unlikely to trigger a new ELM. For pellets arriving later than $20 \mathrm{~ms}$ after the previous ELM the probability is much larger, increasing only slightly with further delay. All pellets seen in the plasma are included in this plot which is correct given that the pellet arrival time is uncorrelated with pellet size or velocity. Figure $9 \mathrm{~b}$ shows a contour plot of the probability of a pellet triggering an ELM as a function of pellet size (given by the camera) and pellet velocity. Here, only pellets arriving more than $25 \mathrm{~ms}$ after the previous ELM have been included. The plot shows that the triggering probability increases more or less linearly with both pellet size and pellet velocity, with $>95 \%$ triggering probability being achieved for the largest pellet sizes and velocities. In this context it should be mentioned that there seems to be no correlation between pellet size and velocity.

The above analysis indicates that, if pellets can be delivered to the plasma without too significant reduction in size and speed and without too much scatter in the arrival time, ELM pacing at up to $50 \mathrm{~Hz}$ seems well

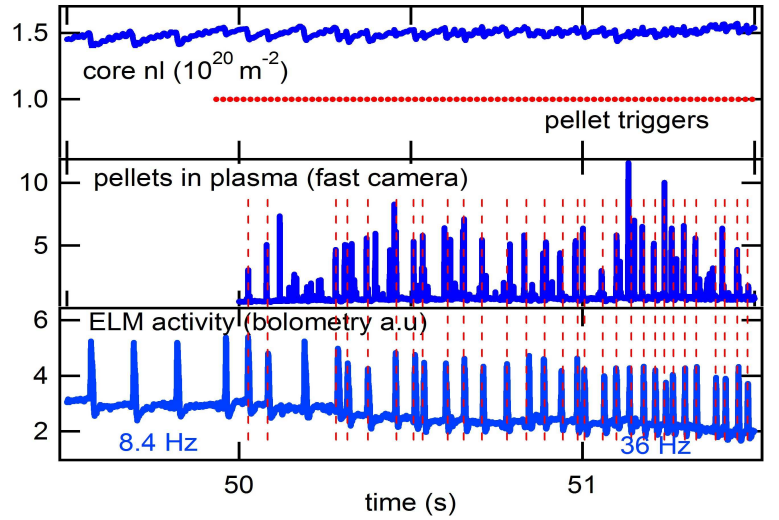

Fig.8 : Pacing with small pellets (JPN 82854) injected at 50 $\mathrm{Hz}$. The ELM frequency is multiplied by a factor up to 4.3

within reach. The proposed improvements described above should go a long way, to achieve this.
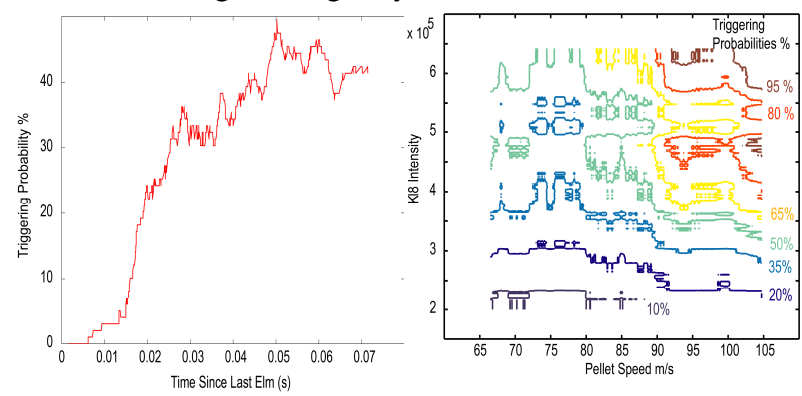

Fig.9 a) Triggering probability as a function of time elapsed since last elm b) Triggering probability as a function of pellet size and speed.

\section{Conclusion}

JET is now equipped with an operational pellet injection system for both plasma fuelling and ELM pacing purposes, having performance close to the ITER requested performance for the same needs. If the injector itself exhibits a good reliability in both modes, important losses are today observed in the flight tubes, in particular in the section installed inside the ICRF antenna and improvements are under consideration.

The results of experiments carried out on plasma so far are rather promising. A first statistical analysis allowed to identify the pellet parameter range leading to a high probability to trigger ELM.

\section{Acknowledgement}

This work, supported by the European Communities under the contract of Association between EURATOM and CEA, was carried out within the framework of the Task Agreement JW5-EP2-TA-HFP-03. The views and Opinions expressed herein do not necessarily reflect those of the European Commission.

\section{References}

[1] Lang P.T. et al., Nuclear Fusion 43 (2003) 1110

[2] Yamada H et al., Fusion Eng. and Design 69 (2003) 11

[3] Geraud A. et al., Fusion Eng. and Design 69 (2003) 5

[4] Vinyar I. et al., Fusion Eng. and Design 86 (2011) 2208

[5] Geraud A. et al., Fusion Eng. and Design 82 (2007) 2183

[6] Combs S.K, et al., Rev. of Scientific Instruments 77 (2006) 